\title{
Optimization of different Parameters of a Gas Lubricated Hydrodynamic Foil Journal Bearing for Maximum Load Carrying capacity with Genetic Algorithm
}

\author{
Mrinal Jyoti Sarma ${ }^{1}$, Ankuran Saha ${ }^{2}$ \\ Assam down town University ${ }^{1,}$, National Institute of Technology Agartala ${ }^{2}$, \\ Email:er.mrinal89@gmail.com ${ }^{1}$, ankuran.saha@gmail.com ${ }^{2}$
}

\begin{abstract}
A study is done based on numerical modeling of the working of a gas lubricated hydrodynamic foil journal bearing in order to find the effects of different parameters involved in its steady state load carrying capacity. The observed results are validated with existed literature. The load carrying capacity is optimized based on the effects of those parameters using Genetic Algorithm Tool in MATLAB. The ranges of tolerance of variation of those parameters are further defined to achieve the optimized load carrying capacity.
\end{abstract}

Index Terms- Load carrying capacity; Genetic Algorithm; Gas foil bearing; MATLAB.

\section{INTRODUCTION}

The standard of performance and efficiency of gas foil bearing is unmatched by any conventional bearing for high speed machineries. These bearings generate a film of gas due to hydrodynamic action to withstand the load from the rotation of the shafts it supports. This modern day bearing design ensures self adjustment of the shaft miss-alignment with inherent internal damping. The foils in these bearing conform to the shape of the mating rotating shaft and provide the compliant feature of the bearing. These gas bearings can be operated at elevated temperatures since viscosity of gas increases with increase in temperature which ensures its application in wide range of operating temperatures. A typical gas foil bearing is shown in fig. 1. It contains a thin layer of top foil supported on the corrugated foil. The leading edge of the bump foil is pivoted to the bearing sleeve and other end is free for providing the compliance effect. The bump foil is provided as single layered or multilayered for varying the compliance effect of the bearing. The corrugated foils come in different configurations like bump type, leaf type, mesh type etc.

The working of the gas lubricated foil bearing is governed by the hydrodynamic action of the working fluid .Initially, when the journal starts spinning, the outer surface of the top foil remains in contact with the bump foil and inside surface with the journal. Once the rotor starts to gain sufficiently higher speeds, the foil pushed away from the journal so that there is no further contact. The separation between the journal and the foil is being maintained by the pressure generated by the rotation of the journal. Hence it becomes evident that the load bearing capacity of the gas foil bearing is dependent on the distribution of pressure in the annular region between the shaft and the foil.

The study of this distribution of pressure and the load bearing capacity is done based on the Reynolds equation for compressible fluid. The solution of the Reynolds equation is obtained by perturbation method (Sahoo [1]) for small $\varepsilon<=0.3$.Milind Babasaheb Patil et.al [2] have stated the steady state performance of a gas foil bearing at different pivoted positions. It is also concluded that the performance of the GFB becomes maximum when the foil is welded at the top position i.e, at $0^{\circ}$. The magnitude of frictional forces developed depends on compliance of the corrugated foils $(\mathrm{Ku}$ and Heshmat [3]. Peng and Carpino developed a model to calculate stiffness and damping co-efficients. The performance of a spring supported compliant foil as the bearing surface is analyzed (Heshmat et. al [3]) and has defined that deflection of the bump foil is equal to the local pressure. Y.B. Lee et. al[4] have found in their work that utilization of visco-elastic material in the top foil of a gas foil bearing improves damping characteristics of the bearing. Lee et al. [5] worked on relation between deflections of the bump foil journal bearings with top foil bending phenomenon and correlation among adjacent bump foil segments. To overcome the startup-shutdown wear problem in sliding bearing Delta Corte et. al [6] have mentioned the use of solid lubricant on top foil inner surface. Kim and Lee [7] have mentioned about an air foil bearing that comprises of both hydrodynamic pressure as well as hydrostatic lift. Andres and Kim[8] developed a finite element model for the top foil and calculated the deformations in top foil and bump strips. Kim et. al. [9] have studied the effect of temperature variation on structural stiffness of a gas foil bearing. Lee et al. [10] showed that the 


\section{Available online at www.ijrat.org}

top foil deflection should be taken into consideration for more reliable estimation of the bump foil bearing behavior.

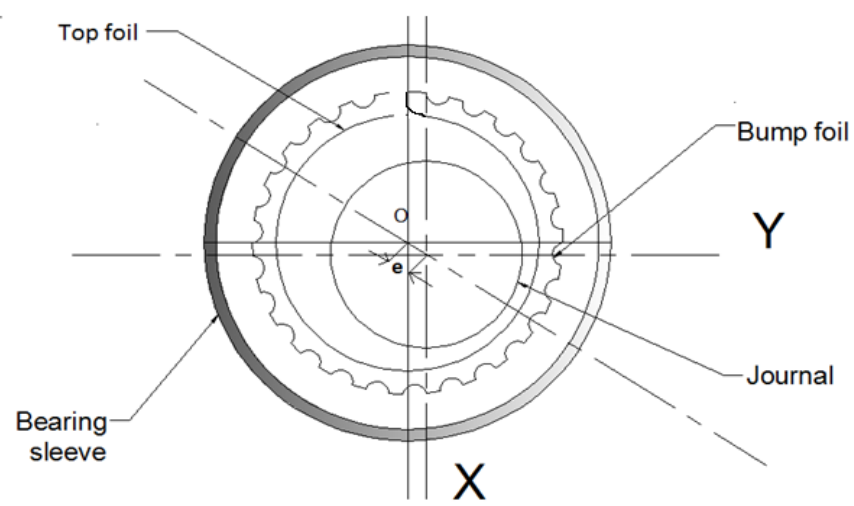

Fig. 1 Schematic diagram of a gas foil bearing

It has been noted from the detailed study of the related technical papers available in the open literature that all the work that have done till now is about the evaluation of performance characteristics of the gas foil bearing considering different bearing parameters. But not much emphasis is put towards the optimized efficiency of the foil bearing with optimization of the parameters effecting it. Hence in the present work an effort has been given to find the optimized efficiency of the gas foil bearing using the GA Tool in MATLAB. Also a range of tolerance of variation of the parameters is defined within which approximately the same optimized load carrying capacity could be attained which would provide an ease of manipulating the design parameters for the design engineers in case of limited resources available.

\section{NOMENCLATURE}

$\theta=$ Angular position on the circumference of the bearing

$\mathrm{R}=$ Radius of the bearing

$\mathrm{C}=$ Nominal clearance

$P \quad=$ Arithmetic mean pressure in the axial direction of the bearing

$p_{a} \quad=$ Atmospheric pressure

$h=$ film thickness of the lubricant

$\mathrm{H}=$ Non-dimensional film thickness of the bearing

$\eta \quad=$ Co-efficient of viscosity of the lubricant

$\delta \quad=$ Bump foil deflection

$\Delta \quad=$ Non-dimensional bump foil thickness

e $=$ Eccentricity

$\epsilon \quad=$ Eccentricity ratio

A $=$ Compliance coefficient of the bump foil material

$\mathrm{P} \quad=$ Non-dimensional arithmetic mean pressure in the axial direction

$\varphi \quad=$ Attitude angle $\omega=$ Angular velocity of the journal

$i, j \quad=$ Co-ordinate system used in the finite difference analysis

$\Lambda$ = Bearing number

$\mathrm{L}=$ Length of the bearing

$\mathrm{D}=$ Diameter of the bearing

\section{METHODOLOGY}

The distribution of pressure in gas foil bearing is governed by a differential equation known as Reynolds equation. The generalized Reynolds equation for a compressible gas undergoing isothermal condition is stated as below

$$
\begin{aligned}
\frac{\partial}{\partial x}\left(\frac{\rho h^{3}}{\eta} \frac{\partial p}{\partial x}\right)+\frac{\partial}{\partial z} & \left(\frac{\rho h^{3}}{\eta} \frac{\partial p}{\partial z}\right) \\
& =6 \mathrm{U} \frac{\partial}{\partial \mathrm{X}}(\rho h)+12 \frac{\partial}{\partial \mathrm{t}}(\rho h)
\end{aligned}
$$

The viscosity of gas does not significantly vary with pressure, hence viscosity can be assumed to be constant.

For a perfect gas,

$$
p=\rho R T \text {; where } \mathrm{R} \text { is gas constant }
$$
and $\mathrm{T}$ is absolute temperature.

If the gas obeys the polytropic relation i.e., $p^{*} \rho^{-n}=$ Constant ; where $n$ is polytropic index.

$$
\begin{aligned}
\frac{\partial}{\partial x}\left(p^{\frac{1}{n}} h^{3} \frac{\partial p}{\partial x}\right)+ & \frac{\partial}{\partial z}\left(p^{\frac{1}{n}} h^{3} \frac{\partial p}{\partial z}\right) \\
& =6 \eta \mathrm{U} \frac{\partial}{\partial \mathrm{X}}\left(p^{\frac{1}{n}} h\right)+12 \eta \frac{\partial}{\partial \mathrm{t}}\left(p^{\frac{1}{n}} h\right)
\end{aligned}
$$

Now, to consider variation of viscosity with pressure it is assumed that gas bearings operate isothermally and for isothermal process $n=1$. 


\section{Available online at www.ijrat.org}

$$
\begin{gathered}
\frac{\partial}{\partial x}\left(p h^{3} \frac{\partial p}{\partial x}\right)+\frac{\partial}{\partial z}\left(p h^{3} \frac{\partial p}{\partial z}\right)=6 \eta \mathrm{U} \frac{\partial}{\partial \mathrm{x}}(\mathrm{ph})+ \\
12 \eta \frac{\partial}{\partial \mathrm{t}}(\mathrm{ph})
\end{gathered}
$$

Now, for a steady flow process the equation further reduces to ...

$$
\begin{gathered}
\frac{\partial}{\partial x}\left(p h^{3} \frac{\partial p}{\partial x}\right)+\frac{\partial}{\partial z}\left(p h^{3} \frac{\partial p}{\partial z}\right)= \\
6 \eta \mathrm{U} \frac{\partial}{\partial \mathrm{X}}(\mathrm{ph})
\end{gathered}
$$

The film thickness $(h)$ varies due to the eccentricity (e) of the journal centre and bearing centre which depends on the radial load of the journal and also due to foil deflection $(\delta)$.

$$
h=c+e \cos (\theta-\varphi)+\delta
$$

The bump foil deflection $(\delta)$ depends on the compliance coefficient $(\alpha)$ and average pressure across the bearing width.

$$
\delta=\alpha\left(\mathrm{p}-p_{a}\right)
$$

The following substitutions are used to form the nondimensional Reynolds equation:

$$
\theta=\frac{x}{r}, \quad \mathrm{Z}=\frac{z}{r}, \quad \mathrm{H}=\frac{h}{c}, \quad \mathrm{p}=\frac{p}{p_{a}},
$$

The non-dimensional Reynolds equation :

$$
\begin{gathered}
\frac{\partial}{\partial X}\left(\mathrm{PH}^{3} \frac{\partial P}{\partial \theta}\right)+\frac{\partial}{\partial Z}\left(\mathrm{PH}^{3} \frac{\partial P}{\partial z}\right)=\Lambda \frac{\partial}{\partial \mathrm{X}}(\mathrm{PH}) \\
\text { where, } \quad \Lambda=\frac{6 \eta \omega r^{2}}{p_{a} c^{2}} \\
\frac{\partial P}{\partial \theta} \cdot \frac{\partial\left(P H^{3}\right)}{\partial \theta}+P H^{3} \frac{\partial^{2} P}{\partial \theta^{2}}+\frac{\partial P}{\partial z} \cdot \frac{\partial\left(P H^{3}\right)}{\partial z} \\
+P H^{3} \frac{\partial^{2} P}{\partial z^{2}}= \\
\Lambda \frac{\partial(P H)}{\partial \theta}
\end{gathered}
$$$$
\mathrm{H}=\frac{\mathrm{h}}{\mathrm{c}}=1+\varepsilon \cos (\theta-\varphi)+\Delta
$$

Equation (7) represents a non-dimensional form of film thickness.

To find the pressure distribution on the journal surface a MATLAB program is written for the computational model based on the boundary conditions given bellow:

$$
\begin{array}{ll}
\text { (i) } & \mathrm{P}=\mathrm{P}_{a} \text { at } \theta=0 \\
\text { (ii) } & \mathrm{P}=\mathrm{P}_{a} \text { at } \theta=2 \pi \\
\text { (iii) } & \mathrm{P}=\mathrm{P}_{a} \text { at } Z= \pm L / 2
\end{array}
$$

Here it is assumed that the initial pressure at all interior nodes as well as the nodes at the boundary of the mesh are equal to $1 \mathrm{~atm}$.

\subsection{Load carrying capacity}

The pressure generated over the journal surface provides a load bearing component along and opposite to the load line. This load bearing component of the distributed pressure can be calculated by numerical integration.

According to the assumed co-ordinate system, the components of the load along the $\mathrm{x}$ and $\mathrm{y}$ axis could expressed as

$$
\begin{aligned}
& W_{x}=\int_{-L / D}^{L / D} \int_{0}^{2 \pi} r P \sin \theta d \theta d z \\
& W_{y}=-\int_{-L / D}^{L / D} \int_{0}^{2 \pi} r P \cos \theta d \theta d z
\end{aligned}
$$

\subsection{Optimization of load carrying capacity}

The Genetic Algorithm tool in MATLAB is used for optimization of the load carrying capacity and values for different parameters such as eccentricity ratio, compliance, angular speed etc. is determined for the optimized results. Here higher "population size" is considered during optimization for better optimized results.

A MATLAB program is further devised to define the range of tolerance of variation of different parameters for allowed $\pm 5 \%$ optimized load bearing capacity so as to ease the design constraints for the various parameters of the bearing.

\section{RESULTS AND DISCUSSIONS}

\subsection{Pressure distribution profile}

The distributions of pressure over the journal surface at different angular positions are plotted in Fig. 3 and have defined the maximum pressure region which is the region around the line of centers of the journal and the bearing.

\subsection{Film thickness profile}

The fig.4 shows the variation of film thickness over different angular positions along the circumference of the bearing. From the graph between Nondimensionalised Film thickness Vs. angular position, it has been noted that the gas film thickness gradually decreases from the inlet position reaches the minimum at the position of line of centers of the bearing and the journal and then starts gradually increasing upto a film thickness nearly equal to inlet film thickness. Hence it is also concluded that film thickness is minimum at the position where non-dimensionalised pressure is maximum.

\subsection{Profile of non-dimensionalised bump foil deflection}

It is observed from the fig.5 that profile of nondimensionalised bump foil deflection over different angular positions is of parabolic nature. It is minimum where the 
International Journal of Research in Advent Technology, Vol.7, No.1, January 2019 E-ISSN: 2321-9637

\section{Available online at www.ijrat.org}

pressure is minimum and maximum where the pressure is maximum. Hence the profile of non-dimensionalised bump foil deflection with respect to pressure plotted in fig.6 is a straight line.

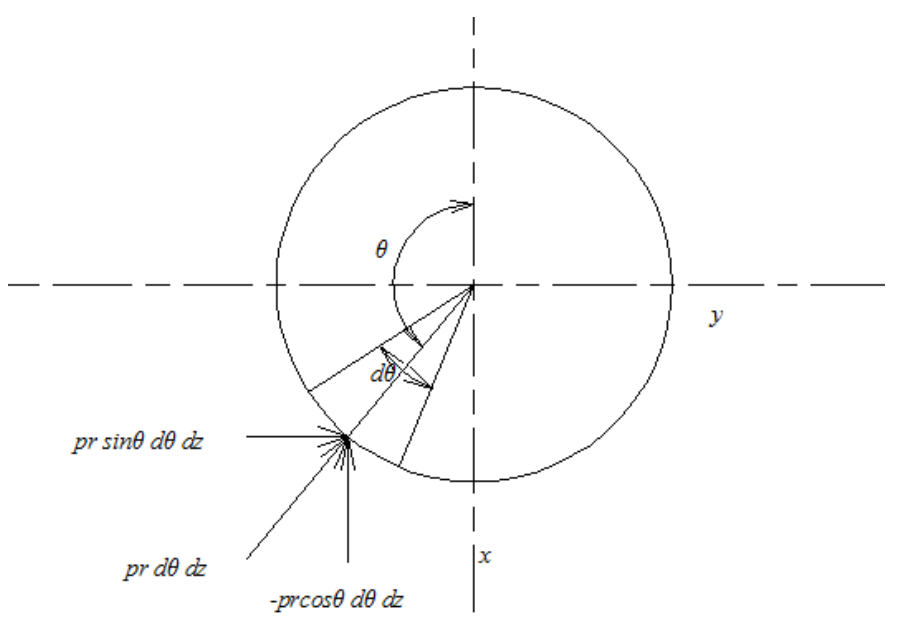

Fig. 2 Free body diagram of the journal

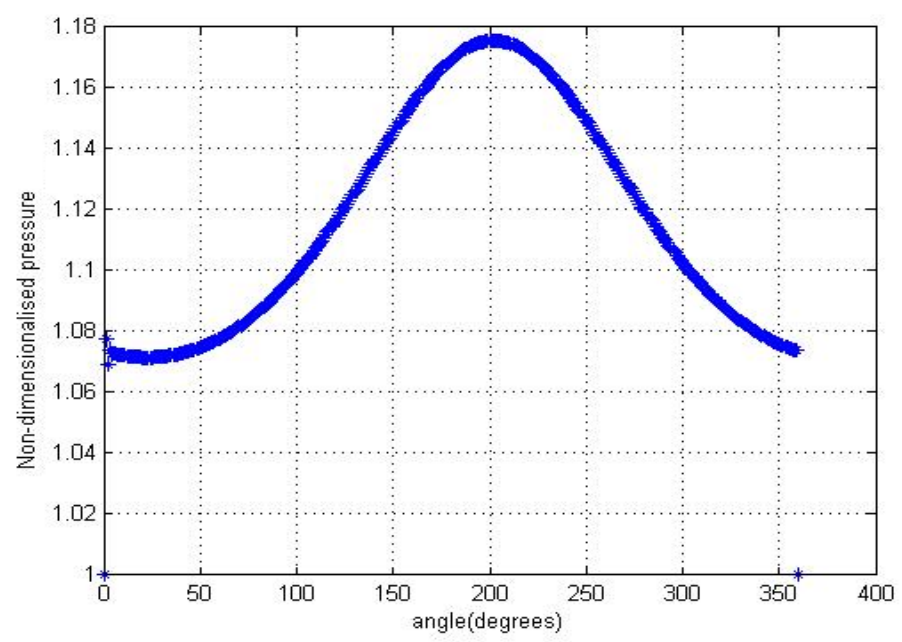

Fig. 3 Non-dimensionalised pressure vs. angular position of the bearing 
International Journal of Research in Advent Technology, Vol.7, No.1, January 2019 E-ISSN: 2321-9637

Available online at www.ijrat.org

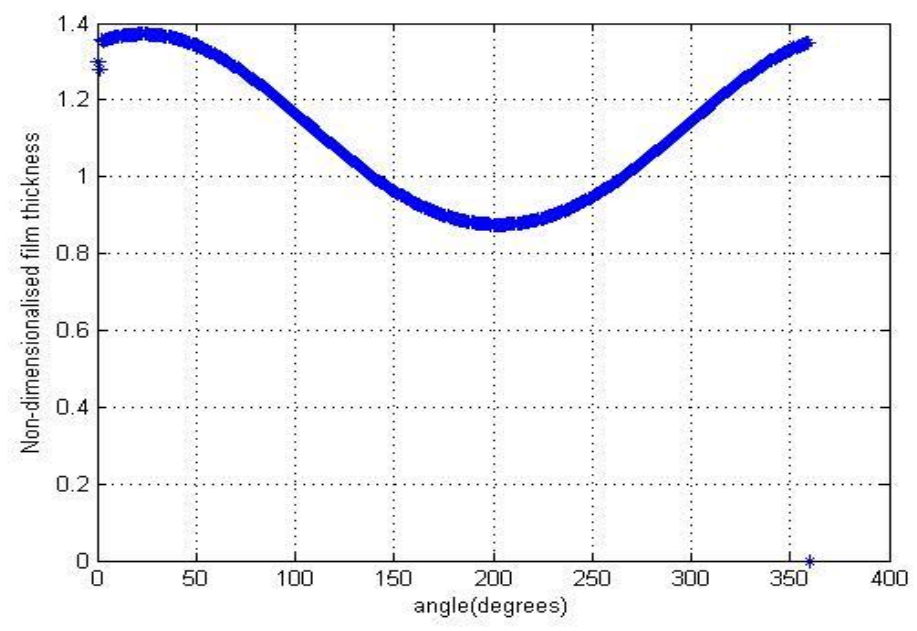

Fig. 4 Non-dimensionalised film thickness vs. angular position

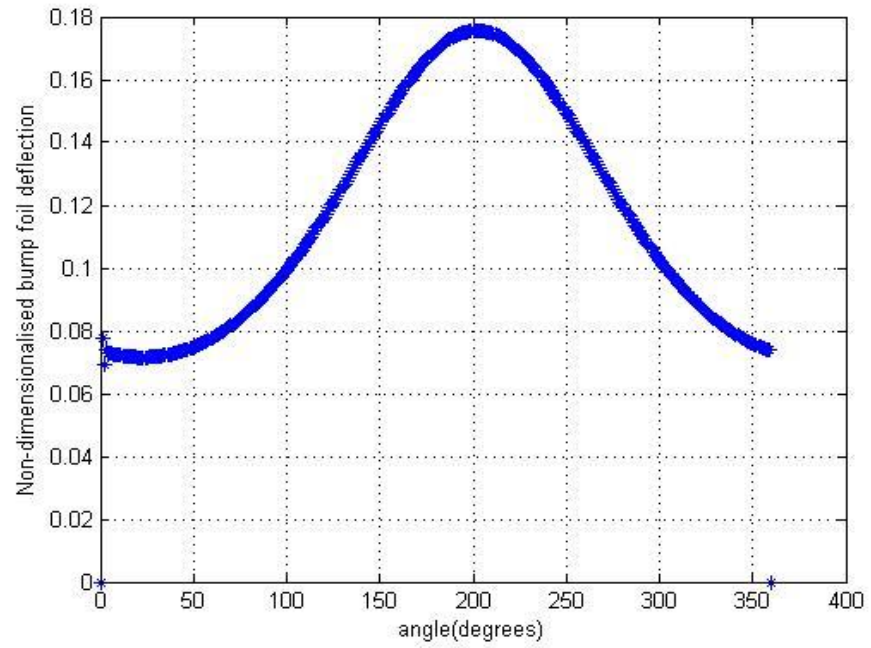

Fig. 5 Non-dimensionalised bump foil deflection Vs. Angular position 


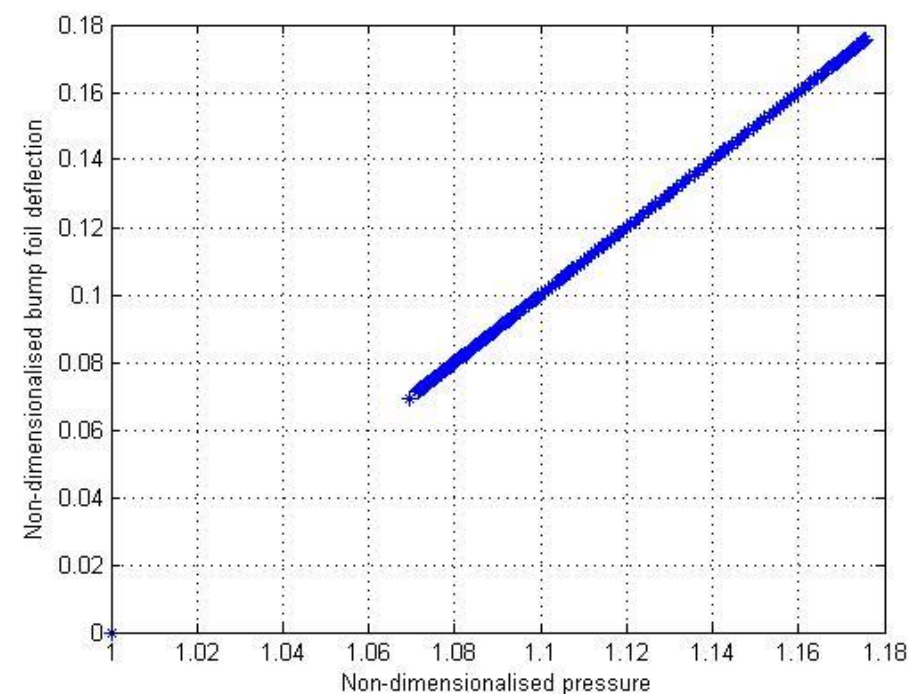

Fig. 6 Non-dimensionalised bump foil deflection Vs. Non-dimensionalised pressure

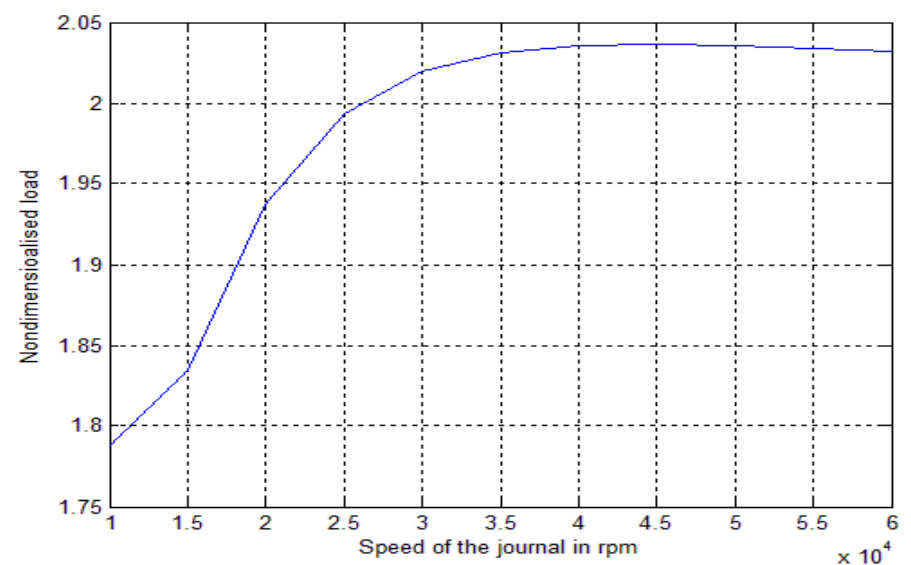

Fig. 7 Non-dimensionalised load Vs. speed of the journal

\subsection{Profile of non-dimensionalised load vs. journal speed}

The plot of non-dimensional load vs. speed of the journal is shown in fig. 7. The load carrying capacity of a bearing is highly influenced by the speed of the journal. While starting a rotor supported by Air foil bearing, initially the journal slides on inside surface of the top foil until it gains a minimum speed to start the hydrodynamic action in the bearing. Hence initially the load carrying capacity is less, but with increase of speed, the load carrying capacity starts to increase up to some limit and then it shows an asymptotic behavior.

\section{OPTIMIZATION OF LOAD CARRYING CAPACITY}

\section{VALIDATION}

The non-dimensional load carrying capacity of a hydrodynamic gas foil bearing depends on various bearing parameters such as length to diameter ratio, eccentricity ratio, compliance, angular speed of the bearing etc. The result of load carrying capacity obtained in the current work is validated(Table 1) with the available open literature. 


\section{Available online at www.ijrat.org}

Table 1. Load carrying capacity for 1, $\alpha=1)$

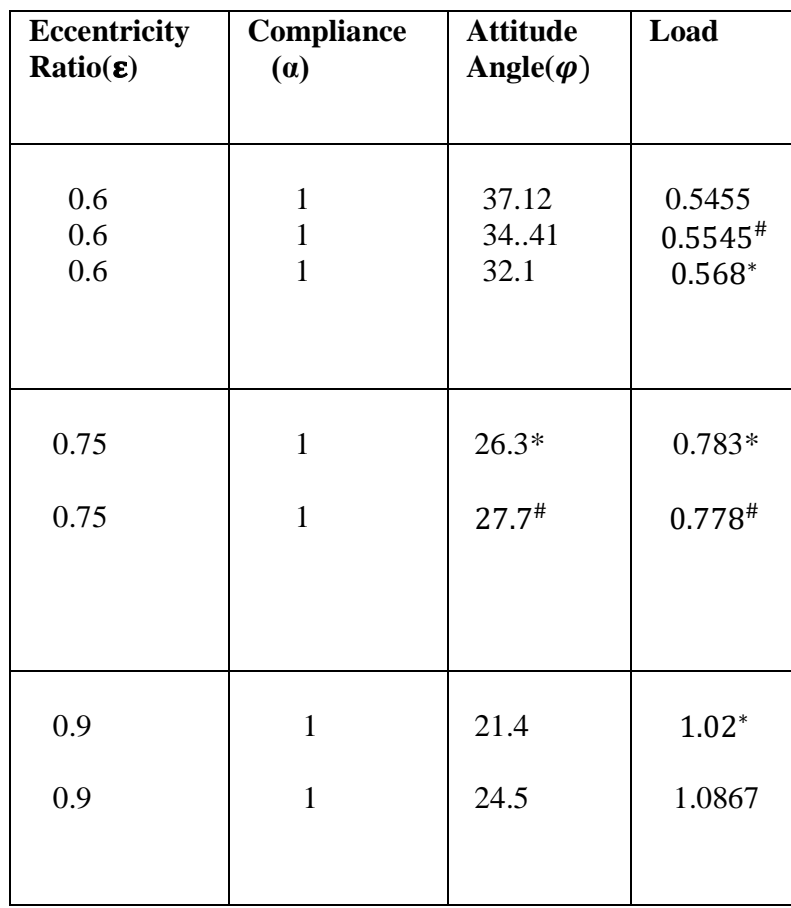

*Heshmat et al.[3]

\#Milind Babasaheb Patil et al.[2]

The optimized load carrying capacity of a hydrodynamic gas foil journal bearing is obtained (Table 3 ) by optimizing bearing parameters like eccentricity $\operatorname{ratio}(\boldsymbol{\varepsilon})$, compliance $(\alpha)$, angular speed of journal $(\omega)$, attitude angle $(\varphi)$ using Genetic Algorithm Tool in MATLAB.

For a short journal bearing of $L / D=1$, compliance $=0.004$, eccentricity ratio $=0.597$, angular speed $=64374.553$ and attitude angle $=10.013$, the optimized load carrying capacity is 3.8854

Table 2. Lower and upper limits of bearing parameters considered while optimization

\begin{tabular}{|l|l|l|}
\hline $\begin{array}{l}\text { Parameters } \\
\text { Name }\end{array}$ & Lower limit & Upper limit \\
\hline Compliance & 0 & 1 \\
\hline Eccentricity ratio & 0 & 0.6 \\
\hline Angular speed & 20000 & 70000 \\
\hline Attitude angle & $5^{\circ}$ & $35^{\circ}$ \\
\hline
\end{tabular}

Table 3. Optimization result for load bearing capacity of a short journal bearing $(L / D=1)$ (Population size $=50, \quad$ stopping criteria $($ generations $=100$, stall generations $=100)$ )

\begin{tabular}{|l|l|l|l|l|}
\hline $\begin{array}{l}\text { Compli- } \\
\text { ance } \\
(\boldsymbol{\alpha})\end{array}$ & $\begin{array}{l}\text { Eccentri- } \\
\text { city } \\
\text { Ratio( } \boldsymbol{\varepsilon})\end{array}$ & $\begin{array}{l}\text { Angular } \\
\text { Speed in } \\
\text { rpm }(\boldsymbol{\omega})\end{array}$ & $\begin{array}{l}\text { Attitude } \\
\operatorname{Angle}(\boldsymbol{\varphi})\end{array}$ & Load \\
\hline 0.004 & 0.597 & 64374.553 & 10.013 & 3.8854 \\
\hline
\end{tabular}

6.1 Range of allowed tolerance of variation of bearing parameters for achieving $\pm 5 \%$ of optimized load carrying capacity

A domain of $\pm 5 \%$ of the bearing parameters is defined in Table 4, so as to ease the design constraints that would at least give $\pm 5 \%$ of optimized load carrying capacity.

Table 4. Range of $\pm 5 \%$ of optimized values of compliance and angular speed for eccentricity ratio $=0.597$, attitude angle $=10.013$ to achieve the optimized load carrying capacity of 3.8854 is tabulated below:

\begin{tabular}{|c|c|c|c|c|c|}
\hline \multirow{2}{*}{$\begin{array}{l}\text { Ecc- } \\
\text { entri } \\
\text { city } \\
\text { ratio } \\
(\varepsilon)\end{array}$} & \multirow{2}{*}{$\begin{array}{l}\text { Attitu } \\
\text { de } \\
\text { angle } \\
(\varphi)\end{array}$} & \multicolumn{2}{|c|}{$\begin{array}{lc} & \text { Range } \\
\text { of } & \text { compliance } \\
(\alpha) & \\
\end{array}$} & \multicolumn{2}{|c|}{$\begin{array}{c}\text { Range of speed } \\
(\omega)\end{array}$} \\
\hline & & Max. & Min. & Max & Min. \\
\hline 0.597 & 10.013 & 0.0043 & 0.00413 & 67500 & 61500 \\
\hline
\end{tabular}

\section{CONCLUSION}

The optimization of steady state load carrying capacity of a hydrodynamic gas foil bearing is done with the help of Genetic Algorithm tool in MATLAB by optimizing different bearing parameters like eccentricity ratio, compliance, angular speed, Attitude angle etc. The ranges of tolerance of variation of these parameters are also defined within which at least $\mathbf{\pm 5} \%$ of optimized load bearing capacity could be achieved which thereby eases the constraints involved in designing high performance gas foil journal bearing. 


\section{REFERENCES}

[1] Sahoo, P.( 2011) "Engineering Tribology" PHI Learning pvt. Ltd.

[2] Patil, M. B.; Kalita, K. and Kakoty, S. K. (2013): Performance Analysis of Gas Foil Bearing with Different Foil Pivot Configuration, Advances in Mechanical Engineering, Volume 2013, Article ID 843419, 9 pages.

[3] Heshmat, H. ; Walowit, J. A. ; and Pinkus, O. (1983): Analysis of gas lubricated foil journal bearings,Journal of LubricationTechnology,vol. 105 , no. 4, pp. 647-655.

[4] Lee, Y.-B. ; Kim, T.-H. ; Kim, C.-H. ; Lee, N.-S. and Choi, D.-H. (2004): Dynamic characteristics of a flexible rotor system supported by a viscoelastic foil bearing (VEFB), Tribology International,vol. 37, no. 9, pp. 679-687.

[5] Lee, Y.-B. ; Park, D.-J. ; Kim, C.-H. and Kim, S.J. (2008):Operating characteristics of the bump foil journal bearings with top foil bending phenomenon and correlation among bump foils",Tribology International, vol. 41, no. 4, pp. 221-233.

[6] DellaCorte, C. ; Zaldana, A. R. and Radil, K. C. (2004): A systems approach to the solid lubrication of foil air bearings for oil-free turbomachinery", Journal of Tribology, vol. 126, no. 1, pp. 200-207.

[7] Kim, D.; Lee, D. (2010): Design of three-pad hybrid air foil bearing and experimental investigation on static performance at zero running speed, Journal of Engineering for Gas Turbines and Power, vol. 132, no. 12, Article ID122504, 10 pages.

[8] Andr'es L. S. ; Kim, T. H. (2008): Forced nonlinear response of gas foil bearing supported rotors, Tribology International, vol. 41, no. 8, pp. 704-715.

[9] Kim, T. H. ;Breedlove, A.W. and Andres, L.S. (2009): Characterization of a foil bearing structure at increasing temperatures : static load and dynamic force performance, Journal of Tribology, vol. 131,no. 4, Article ID041703, 9 pages.

[10]Lee, Y.B. ; Park, D.J. ; Kim, C.H. and Kim, S.J. (2008): Operating characteristics of the bump foil journal bearings with top foil bending phenomenon and correlation among bump foils, Tribology of internationals, vol. 41, no. 4, pp. 221-233. 